\section{Por uma epistemologia da prática do jornalismo orientado à imersão}

\author{
Adalton dos Anjos Fonseca
}

\section{Resumo:}

Este artigo tem como objetivo propor uma epistemologia da prática jornalística orientada à imersão. Parte-se da observação de que determinadas produções jornalísticas em plataformas digitais investem mais em recursos e estratégias para dar conta da categoria imersão do que outras. Explora-se uma abordagem metodológica qualitativa, com estudos de caso escolhidos tendo como base premiações de peças jornalísticas nacionais e internacionais. Dois produtos dos meios jornalísticos Correio $^{*}$ e The Guardian compuseram o corpus. Entrevistas semiestruturadas com profissionais de cada peça foram realizadas. Os resultados indicam que uma epistemologia da prática do jornalismo em redes digitais que investe na imersão tem como especificidade modos de operação e uma disponibilidade dos agentes produtivos que valorizam a experiência.

Palavras-chave: Imersão. Jornalismo. Epistemologia.

\section{For an epistemology of immersion oriented journalism practice}

\begin{abstract}
:
This article aims to propose an epistemology of journalistic practice oriented to immersion. It starts with the observation that certain journalistic productions on digital platforms invest more in resources and strategies to cope with the immersion category than others. We explore a qualitative methodological approach with case studies chosen based on awards from national and international journalistic pieces. Two media products, Correio ${ }^{*}$ and The Guardian, compose the corpus. We conducted semi-structured interviews with professionals from each piece. The results indicate that an epistemology of the practice of journalism in digital networks that invests in immersion has specific modes of operation and an availability of the productive agents that value the experience.
\end{abstract}

Keywords: Immersion. Journalism. Epistemology.
Recebido em: 10.09 .20

Aprovado em: 10.09.21

\section{Adalton dos Anjos \\ Fonseca}

Doutor em Comunicação e Cultura Contemporâneas pela UFBA. Membro do Grupo de Pesquisa em Jornalismo On-line (GJOL-UFBA)

E-mail: adalton.anjos@ gmail.com 


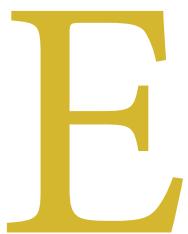

sforços de investigação que se dedicam a propor um estudo epistemológico da prática jornalística estão em busca de identificar a forma de conhecimento gerada pelo jornalismo. Ettema e Glasser (1984) defendiam que o jornalismo investigativo concentrava determinados elementos que alteravam a aquisição de conhecimento da atividade. Ekström (2002) identificou outras características nesta mesma linha que emergiram a partir do telejornalismo. Consequências epistêmicas também movimentaram análises sobre a relação com os blogs (MATHESON, 2004), o big data (LEWIS; WESTLUND, 2015), os dados (SPLENDORE, 2016), os algoritmos (CARLSON, 2018; 2020) e os live-blogging (MATHESON; WAHL-JORGENSEN, 2020). Este artigo, que deriva dos resultados da nossa pesquisa doutoral (FONSECA, 2020), busca propor uma epistemologia da prática do jornalismo orientado à imersão.

Parte-se do argumento que a imersão é uma categoria estruturante do jornalismo. Uma revisão teórica deste conceito em diferentes tradições de pesquisa (GRAU, 2003; MACHADO, 2002; MURRAY, 1997; RYAN, 2015) mostra que deslocamentos do espaço-tempo entre acontecimentos ficcionais ou não-ficcionais e mentes imaginativas estão por trás da imersão de sujeitos em uma dada história. Tendo como foco o campo jornalístico (BOURDIEU, 1997), uma observação cuidadosa da práxis jornalística e de suas consequências demonstram que processos análogos ao da imersão ocorrem em múltiplos níveis e dimensões - fonte e repórter, repórter e editor, produto e leitores/telespectadores/ouvintes/usuários.

Narrativas jornalísticas orientadas à imersão caracterizam peças e suas respectivas produções que estão empenhadas na oferta de recursos que incrementam a imersão. São produtos configurados de modo a partilhar a complexidade do mundo de forma detalhada, contextualizada, não-fragmentada, com a combinação de formatos narrativos e tempo alargado de produção e fruição (FONSECA, 2020). Neste sentido, a questão que norteia este artigo procura identificar as particularidades deste tipo de prática orientada à imersão no que diz respeito à produção de conhecimento.

Metodologicamente, este artigo tem uma abordagem qualitativa e explora os estudos de caso como caminho porque investigamos "[...] um fenômeno contemporâneo dentro do seu contexto da vida real” (YIN, 2015, p. 32). Os casos escolhidos trazem elementos, problemas, conflitos e eventos que são representativos para o campo jornalístico, conforme recomendações de Dooley (2002). As peças analisadas foram publicadas por um meio local, Correio* (BA), e outro internacional, The Guardian (Reino Unido). Entrevistas semiestruturadas foram realizadas com os respectivos agentes produtivos. Em acordo com os participantes, as respostas que subsidiam este trabalho não serão identificadas.

\section{Epistemologias do jornalismo}

De tradição filosófica, a epistemologia ou teoria do conhecimento é uma disciplina cujo objeto de estudo é a ciência. Segundo Castañon (2007), métodos, história, critérios, funcionamento e organização do conhecimento sistemático são avaliados no sentido de verificar as bases principais que definem a verdade na ciência. A epistemologia ou teoria do conhecimento "[...] é o estudo geral dos métodos, história, critérios, funcionamento e organização do conhecimento sistemático, seja ele especulativo (teologia e filosofia) ou científico" (CASTAÑON, 2007, p. 13). Neste sentido, o estudo epistemológico é interdisciplinar, pode ser global ou específico, pode encaminhar por linhas de trabalhos baseadas na lógica, linguística, sociologia, política e história, além de seguir concepções empíricas, racionalistas, construtivistas, materialistas, críticas, históricas, idealistas, entre outras.

No jornalismo, Park (1940) reflete sobre a maneira específica que esta atividade tem de produzir e reproduzir conhecimento, que entra em confronto com o 
modelo positivista de construção da "verdade científica". Segundo ele, existe o "conhecimento sobre", produzido formalmente pela ciência, e o "conhecimento de", proveniente do senso comum. Meditsch (2002) alerta que o jornalismo trabalha com o conhecimento do senso comum e partilhas sociais do cotidiano que o tornam menos rigoroso e menos artificial do que a ciência formal. Ao mesmo tempo, porém, a notícia tem um determinado lugar e formas de produção, embora não tão sistematizadas como o conhecimento científico. A universalidade ilustra as semelhanças e particularidades nas duas formas de conhecimento descritas em Meditsch (2002). Na ciência, a linguagem formal, um ponto de partida baseado em hipóteses, experimentações e observações controladas são protocolos universais para que a comunidade científica possa validar um conhecimento. No jornalismo, a universalidade está ligada à amplitude do público ao qual se destina um produto noticioso, o que acarreta problemas como a falta de transparência na definição de pautas, a velocidade de produção e até as estratégias de espetacularização, já que é preciso capturar a atenção e persuadir os leitores (MEDITSCH, 2002).

A singularidade é outro conceito por trás da caracterização do processo jornalístico de apreensão da realidade e geração do conhecimento. "O singular é matéria-prima do jornalismo, a forma pela qual se cristalizam as informações ou, pelo menos, para onde tende essa cristalização e convergem as determinações particulares e universais" (GENRO FILHO, 1987, p.183). O autor defende que esta categoria central da teoria do jornalismo provoca uma forma de percepção fragmentada e descontextualizada da realidade em uma estratégia alinhada com a ideologia burguesa.

Para além de uma perspectiva filosófica, Rudiger (2014) relata que a epistemologia também pode estar relacionada a uma atividade ou a própria vida cotidiana. Nestes termos, ela é acionada como um instrumento da sociologia do conhecimento - abordagem que não converge com o percurso do autor, mas está alinhada com nosso objetivo.

Levisolo (2008) nos convoca a seguir um caminho de análise cujo olhar esteja centrado na prática dos participantes de um campo particular. A "epistemologia prática" está preocupada em compreender os processos que ocorrem na relação sujeito/objeto de conhecimento, como os membros novos e as suas interações com as tradições. Em suma, o foco da observação está em três temas: a) funções, papéis e valores que orientam os sujeitos; b) procedimentos e técnicas; c) a relação ou coerência entre a e b.

Ettema e Glasser (1984) e Ekström e Westlund (2019) também optam pela vertente sociológica em suas empreitadas para o exame epistemológico de fenômenos ligados ao jornalismo. Segundo a definição operacional de Ekström (2002, p. $260)$, "[...] a epistemologia refere-se às regras, rotinas e procedimentos institucionalizados que operam dentro de um ambiente social e decidem a forma do conhecimento produzido e as afirmações de conhecimento expressas (ou respondidas)".

A objetividade (CHALABY, 1998; GUERRA, 1998; MARAS, 2013; SPONHOLZ, 2009; TUCHMAN, 1972) traduz um modelo epistêmico que é hegemônico entre a atividade e é indicado por Tambosi (2003) como aquele que define um estatuto epistemológico para o jornalismo. Ao traçar um diagnóstico complexo do conceito, Maras (2013) explica que ele está ligado às diferentes formações culturais e, portanto, não emerge do mesmo modo e de forma simultânea nos vários países. Outra observação do autor é a hegemonia do modelo estadunidense baseado na separação entre fato e opinião, distanciamento emocional das notícias, justiça e equilíbrio.

O conhecimento jornalístico baseado na objetividade, segundo Labasse (2017), tem como obstáculos o fato de que a apuração jornalística é imperfeita, subjetiva, desigual e com escolhas nem sempre evidentes. Além disso, de acordo com ele, o profissional não está legitimado a tratar e questionar muitos assuntos que reporta e fica nas mãos das fontes. A solução para este impasse, para Durham

${ }^{1}$ Todas as traduções foram feitas pelo autor. 
(1998), está na proposta da "epistemologia do ponto de vista". O contexto desta formulação está nos debates do movimento feminista, que ajuda a alertar sobre a qualidade das coberturas jornalísticas de grupos marginalizados.

\begin{abstract}
A epistemologia do ponto de vista oferece à prática do jornalismo um meio de torná-la significativamente conectada com a vida política diária. Ela também permite esperança para a realização dos objetivos libertários do jornalismo em promover um método para questionar e desafiar relações de poder na sociedade via produção de notícias (DURHAM, 1998, p. 134).
\end{abstract}

A proposta rompe com elementos prescritos pela postura objetiva no processo jornalístico e, ao mesmo tempo, se mantém unificada com um ativo importante da atividade que é a busca por uma produção de conhecimento verossímil. Modelos de meios noticiosos como Gênero e Número e Infoamazônia, especializados no debate sobre as questões de gênero e as ambientais respectivamente, por exemplo, constroem autoridade jornalística (CARLSON, 2017) com base na epistemologia do ponto de vista ao definirem previamente e abertamente seus modos de existência no embate com agentes sociais em defesa dos direitos das minorias.

Este exercício sugerido por Durham (1998) foi aplicado e estendido por Cremilda Medina com a experiência do São Paulo de Perfil - conjunto de livros-reportagem produzido por alunos ao longo de 27 edições. Buscava-se romper com métodos tradicionais, factuais e institucionalizados por uma indústria jornalística que entregava produtos noticiosos burocráticos, superficiais, pouco originais, conservadores e desumanizadores (MEDINA, 2003). A autora fala em uma "epistemologia do diálogo social", que busca validar o conhecimento dos eventos a partir de várias angulações e contextos, e demanda uma ampla visão de mundo do repórter para compreender este complexo mundo social (MEDINA, 2014).

No fundo destas discussões está uma crítica em torno do modelo da objetividade jornalística como o garantidor da qualidade desta forma de conhecimento. A epistemologia do jornalismo investigativo de Ettema e Glasser (1984) ressalta uma especificidade da produção noticiosa pelo jornalismo cotidiano baseado na objetividade em relação ao modelo que investe em investigação que é bastante importante do ponto de vista epistemológico. Segundo eles, notícias factuais demandam do repórter a busca por precisão e não veracidade. Desta forma, quando o jornalismo investigativo vai além das declarações, ele atesta a veracidade de cada proposição.

Para autores como Godler, Reich e Miller (2020), um novo paradigma epistêmico para o jornalismo estaria emergindo a partir da exploração dos dados no processo de circulação de notícias. Segundo eles, o conhecimento jornalístico estaria sendo influenciado por recursos tecnológicos capazes de capturar movimentos de sociabilidade nas mídias sociais. Assim, a "epistemologia social" se preocupa em estudar o conhecimento gestado a partir da relação com instituições e testemunhos, ou seja, conhecimentos de segunda mão, e suas implicações sociais na compreensão dos sujeitos.

O telejornalismo também foi tema de estudo quanto à especificidade da sua forma de conhecimento. Ekstrom (2002) propôs um framework teórico para distinguir três áreas da epistemologia do jornalismo, quais sejam: como forma de conhecimento, como produção de conhecimento e pela aceitação do conhecimento pelo público. Desta forma, o telejornalismo é uma forma de conhecimento porque oferece um modo específico de entender a realidade cotidiana que une o meio televisão com várias regras, modelos e gêneros. Combina-se a informação com texto e imagem de modo que aproxima o jornalismo do campo da arte e da publicidade; explora-se a emoção, simplifica-se a mensagem para atingir a todos massivamente, empreende-se estratégias que criam laços emocionais, constrói-se eventos extraordinários e recorre-se à imediaticidade e à transitoriedade do conhecimento. 
Ainda segundo o autor, como produção de conhecimento, o telejornalismo está estabilizado com base em normas e técnicas que o fazem conquistar autoridade jornalística para que suas emissões sejam consideradas verdadeiras. Na próxima seção, abordaremos as características de produções jornalísticas orientadas à imersão.

\section{Narrativas jornalísticas orientadas à imersão}

Em Fonseca (2020), argumenta-se que a relação entre imersão e jornalismo é mais complexa do que os conceitos de jornalismo imersivo (DE LA PEÑA et al., 2010), jornalismo de imersão (LÓPEZ HIDALGO; FERNÁNDEZ BARRERO, 2016; TÁRCIA, 2011) ou jornalismo etnográfico (CRAMER; MCDEVITT, 2004; HERMANN, 2016) descrevem. No primeiro caso, o foco está no uso de tecnologia de realidade virtual que possibilite aos usuários experiências em primeira pessoa com notícias como se elas estivessem presentes em outro espaço-tempo. No segundo e terceiro casos, as investigações se concentram em analisar estratégias na fase de produção jornalística.

A proposta da imersão como categoria estruturante do jornalismo é ampla o suficiente para englobar as diferentes dimensões do processo jornalístico e indicar um caminho de pesquisa sobre a atividade que tenta dar conta de diversas particularidades. Ela parte de uma rigorosa revisão bibliográfica em torno do conceito de imersão em diferentes tradições de pesquisa, como a psicologia (BOUKO, 2014), jogos (BIZZOCCHI, 2007; BROWN; CAIRNS, 2004; ERMI; MÄYRÄ, 2005), estudos literários e narratologia (MURRAY, 1997; RYAN, 2013; 2015), história da arte e historiografia (ALLAN; DE JONG; DE JONGE, 2017; GRAU, 2003), entre outros. Estes múltiplos estudos abordam a natureza multidimensional da imersão, incluindo a importância das técnicas e tecnologias exploradas na produção e apresentação da narrativa e de todo o amplo conjunto de variáveis contextuais que envolvem os sujeitos.

Em suma, o termo imersão, que remete ao ato de mergulhar ou submergir, passou a ser usado de forma metaforizada para explicar o deslocamento de mentes imaginativas no espaço-tempo por meio de uma narrativa, ou seja, uma viagem tão profunda que faz com que o sujeito "mergulhe" ou tenha a sensação de estar em outro lugar (GERRIG, 1993; MURRAY, 1997; RYAN, 2015). A narrativa jornalística visa compartilhar acontecimentos do mundo cotidiano com sujeitos que, na maioria das vezes, não estiveram presentes fisicamente no momento do ocorrido. No cerne desta atividade profissional estão diversas dimensões alinhadas com a imersão que permitirão a locomoção mental dos sujeitos em níveis mais superficiais ou profundos. Este conceito, portanto, faz parte do "modo de ser" da própria atividade, está em relação com outros agentes que constroem e reconstroem o jornalismo, estrutura limites, mudanças, formas de atuação de cada membro do grupo e hierarquiza.

Um olhar em perspectiva histórica mostra que o jornalismo tem sua trajetória marcada por uma série de evoluções técnicas, narrativas, laborais, deontológicas e mercadológicas mobilizadas também com a intenção de aprimorar processos de imersão com produções jornalísticas. O novo jornalismo estadunidense (BRAGATTO, 2007; LIMA, 1993; MARTINEZ, 2017), o testimonio latino-americano (ASSUNÇÃO, 2016; GARCÍA, 2009) ou grandes reportagens multimídia que exploram diferentes recursos da plataforma digital como a multimidialidade (DEUZE, 2004; SALAVERRÍA, 2014) e/ou a hipertextualidade (MIELNICZUK, 2003), como Snow Fall ${ }^{2}$ (BRANCH, 2012) do The New York Times, por exemplo, possuem características que as orientam em direção à imersão.

Narrativas jornalísticas digitais orientadas à imersão são caracterizadas por terem: a) um maior tempo de produção e apuração cuidadosa; b) um relato

${ }^{2}$ A peça foi publicada em 2012. Disponível em: http://www.nytimes.com/ projects/2012/snow-fall/ index.html. Acesso em: 08 jan. 2020. 
aprofundado, não-fragmentado, contextualizado e com prosa criativa; e c) um uso estratégico de recursos da plataforma digital, no sentido descrito pelos autores que investigam a Convergência Jornalística (FONSECA, 2015; GORDON, 2003; KOLODZY, 2012; SINGER, 2004) ao acionarem a interatividade, multimidialidade, hipertextualidade, participação, bases de dados, entre outros. Além disso, estes produtos geralmente tratam de temáticas complexas, histórias de interesse humano, demandam maior tempo para fruição e exigem estratégias de captura da atenção que vão além do número de visitantes (FONSECA, 2020).

Por conta de todas estas características, entendemos que a produção de peças jornalísticas orientadas à imersão requisitam procedimentos, posturas profissionais e institucionais com impactos diretos na geração de conhecimento jornalístico. Ao buscar uma conexão profunda e temporalmente mais durável com usuários, toda a escala de decisões editoriais tomadas - desde a escolha da pauta, passando pelos agentes produtivos e estratégias de circulação - tem atributos específicos e frequentemente estão alinhados com expectativas baseadas no ideal de serviço público (PEW, 1931), regra da transparência (MAIA, 2008), foro público (SCHUDSON, 2008). São produtos tidos como referência no campo jornalístico, indicados à premiações nacionais e internacionais, que provocam mudanças sociais e agregam capital social ao meio jornalístico.

\section{Particularidades da práxis jornalística orientada à imersão}

Duas peças jornalísticas foram escolhidas para compor o corpus empírico deste artigo. O material explorado é uma parte da nossa pesquisa doutoral (FONSECA, 2020). A partir de um levantamento de produtos publicados em meios jornalísticos internacionais e nacionais indicados em premiações, e trabalhos acadêmicos listados como exemplos em sites de metajornalismo, montamos uma planilha online ${ }^{3}$ para catalogar as informações. Uma nova filtragem foi realizada tendo em vista o entendimento sobre o jornalismo orientado à imersão. Os produtos foram analisados em suas características narrativas e entrevistas semiestruturadas foram realizadas com os respectivos agentes produtivos. Conforme solicitação dos entrevistados, as respostas não serão identificadas. Apresentaremos brevemente cada um dos produtos:

a) Correio*: A GRM "Silêncio das inocentes" foi publicada em 9 de dezembro de 2015. A peça aborda o tema da violência sexual contra a mulher. Dados sobre os casos de estupro, testemunho de diversas vítimas de violência, delegados e fontes especializadas ajudam a compor a peça. Entre os formatos narrativos explorados estão o texto escrito, mapa interativo, o áudio, a fotografia e o vídeo. $\mathrm{O}$ agente produtivo entrevistado pessoalmente no dia 7 de fevereiro de 2019 foi Juan Torres, o editor do produto.

b) The Guardian: $\mathrm{O}$ vídeo $360^{\circ}$ The Party: the virtual experience of autism foi publicado no dia 7 de outubro de 2017. A peça trata do transtorno do espectro autista colocando o usuário no lugar de Layla, uma garota de 14 anos, durante a festa de aniversário da sua mãe. No meio da festa, temos acesso aos pensamentos da personagem, suas angústias e medos. A peça simula a forma como a garota enxerga e escuta. A agente produtiva, entrevistada por e-mail no dia 31 de janeiro de 2019, foi Shehani Fernando,

${ }^{3}$ A planilha está disponível no link a seguir: https:// docs.google.com/spreadsheets/d/1Vo_J2vfR0Q1nUdEkyiWENcZkelHYgTomo05S9aLcIbE/edit\#gid=0 diretora de experiências em realidade virtual.

Os produtos analisados são uma GRM, que explora múltiplos formatos narrativos e recursos das plataformas digitais (HIIPPALA, 2017; LONGHI; WINQUES, 2015), bem como um vídeo $360^{\circ}$ - formato considerado uma modalidade 
de realidade virtual que permite uma experiência audiovisual em primeira pessoa (BENÍTEZ DE GRACIA; HERRERA DAMAS, 2017; HODGSON, 2017). Ambas carregam uma série de decisões editoriais e escolhas narrativas, como algum nível de ruptura com relação aos modelos de trabalho jornalísticos, baseados em valores como a objetividade, autonomia, transparência e instantaneidade (DEUZE, 2008; DEUZE; WITSCHGE, 2018).

Do ponto de vista da objetividade como procedimento, percebeu-se a adoção de estratégias e técnicas de apuração que combinaram uma variedade de fontes - 50 pessoas foram entrevistadas na peça do Correio $^{\star}-$, menor distanciamento entre repórteres e fontes e não priorização de fontes primárias. Grupos focais para a discussão com envolvidos direta ou indiretamente com o tema da pauta produzida pelo The Guardian também foram explorados e tiveram impactos na geração de conhecimento jornalístico, já que estes encontros tinham como consequência a construção coletiva deste conhecimento no momento da apuração com a troca de informação entre os participantes. Desta forma, buscou-se combinar um amplo volume de percepções individuais, resultados de observações científicas e recursos tecnológicos e narrativos para a configuração de um produto em vídeo $360^{\circ} \mathrm{capaz}$ de oferecer o acesso a um tipo de conhecimento que se ancora no despertar de sentimentos como a empatia.

O tempo de produção é outra característica que possibilita um contato mais próximo e alargado entre repórter e fontes. Em um dos casos analisados, foram quatro meses de trabalho até a publicação, enquanto em outro, foram necessários sete meses entre produção e disponibilização para o público. O editor de uma das reportagens relatou que teve dificuldades em definir a estrutura narrativa da peça pelo volume de material apurado inicialmente. Entretanto, ele também destacou a importância deste movimento de aprofundar a informação, capturar a expressão, tom de voz, ambiente e reações das diferentes fontes para um relato mais verossímil.

Por outro lado, este tempo mais alargado na produção está em contradição com um dos atributos da produção jornalística em redes digitais, a instantaneidade. Bradshaw (2014) e Canavilhas (2007), por exemplo, trazem vários aspectos referentes às rotinas de produção e aos produtos como a publicação de notícias em tempo real. Assim, esta relação com o tempo de produção que está alinhada com esforços que buscam fomentar a imersão e, ao mesmo tempo, na contramão do modelo industrial do jornalismo molda decisões e resultados do trabalho jornalístico. É possível diversificar métodos de apuração e realizar análises de dados ou observação participante para contrapor, checar e contextualizar declarações dadas em entrevistas, bem como superar estratégias de produção noticiosa que se baseiam em fontes oficiais.

A autonomia é um valor jornalístico que também assume diferentes características em produtos noticiosos orientados à imersão. Com equipes maiores, as decisões sobre a produção das peças analisadas precisaram ser compartilhadas, embora tenhamos observado que repórteres e editores continuam sendo condutores deste grupo. No caso do vídeo $360^{\circ}$ do The Guardian, além dos 25 atores que compõem a simulação, diretores, produtores executivos, tecnólogos e consultores somam 36 profissionais listados no expediente.

Preocupações na produção, para que decisões sobre o andamento das narrativas sejam tomadas pelos usuários, também impactam o valor da autonomia. Este é um aspecto da relação entre jornalismo e as plataformas digitais desde meados dos anos 1990. Murray (1997) refere-se ao "prazer de transformação" permitido pelos recursos digitais quando explorados pelos agentes produtivos, como sendo aquele capaz de libertar o leitor das amarras do autor e definir os rumos da sua experiência na interação com uma narrativa. Observamos que recursos como o hiperlink, que permitiram a navegação no mapa interativo da GRM do Correio* ${ }^{\star}$ e a escolha de enquadramentos em narrativas imersivas, como a do The Guardian, 
por exemplo, fazem com que determinadas decisões sobre o percurso da narrativa sejam tomadas também pelos usuários.

A transparência foi notada ao longo da análise de diferentes formas. Por um lado, o produto do Correio ${ }^{\star}$ esteve alinhado com a "Regra da Transparência", que, segundo Kovach e Rosenstiel (2001), refere-se à necessidade de informar aspectos de bastidores do processo de produção, fontes de dados e possíveis conflitos de interesse. No meio local, por exemplo, repórteres e editor publicaram depoimentos em áudio relatando suas experiências no processo de produção reportagem - a violência sexual contra a mulher - de modo bastante pessoal. Entretanto, verificamos que no caso do The Guardian houve uma omissão de informações que vão na contramão deste valor. A peça inteira está fundamentada em uma simulação e não traz lide, dados, referenciais temporais e de espaço, fontes documentais e pessoais consultadas. Além disso, não fica evidente no vídeo $360^{\circ}$ que se trata de uma encenação conduzida por diretores em um set de gravação, com a participação de atores que ensaiaram cada movimento.

Autonomia compartilhada na interação e a transparência, ainda que limitadas nos casos analisados, forjam uma sensação de não-mediação entre o acontecimento narrado e o sujeito, e buscam potencializar a experiência de imersão no processo de decodificação. A estratégia usada na configuração destas peças é simular como se daria a interação com o mundo físico. Os impactos no conhecimento jornalístico estão ligados à necessidade de acionamento de diferentes sensorialidades e múltiplas camadas de informação, em oposição a caminhos que indicam a omissão das emoções, neutralidade e concisão.

Por fim, foi identificado que a disputa por atenção coletiva não é o primeiro objetivo deste tipo de trabalho, segundo seus agentes produtivos. Estes produtos especiais ocupam um lugar diferente no ambiente das organizações. De acordo com eles, são peças feitas para o usuário imergir, para os meios experimentarem e para agregar valor às respectivas marcas jornalísticas porque alimentam o discurso da inovação no campo jornalístico e, frequentemente, são laureadas - como nos casos analisados no presente artigo.

\section{Proposta de uma epistemologia da prática do jornalismo orientado à imersão}

Diante dos casos analisados, é possível perceber que uma série de decisões das peças jornalísticas orientadas à imersão não está em consonância com a epistemologia dominante da objetividade, baseada no modelo estadunidense (MARAS, 2013; SPONHOLZ, 2009). A validação do conhecimento produzido pelo jornalismo nestes tipos de produtos acionam valores e normas de modos diferentes.

Fonseca (2020) defende que acordos da ordem da intersubjetividade entre agentes produtivos e sujeitos/fontes/usuários são importantes para a validação do conhecimento jornalístico. Este sentido comum, produzido socialmente a partir do cruzamento de subjetividades diferentes (PIVA et. al. 2010; SPONHOLZ, 2009), permite o compartilhamento de mundos entre jornalistas e fontes e, posteriormente, deslocamentos mentais no tempo e espaço por meio de narrativas configuradas. Na prática, estamos nos referindo a modelos como o jornalismo etnográfico ou de imersão, descritos por Cramer e McDevitt (2004) ou Herman (2016), por exemplo.

A viabilização de um trabalho jornalístico que aciona acordos intersubjetivos perpassa por um modus operandi baseado no dialogismo, discutido em Durham (1998), e pela convocação do recurso do testemunho. O encontro entre fontes e repórteres permite uma troca de conhecimentos entre as partes pela forma como é articulado. Há um tempo maior neste contato, quase sempre presencial, uma preparação mais cuidadosa do entrevistador para a formulação das perguntas e estratégias para coleta de elementos contextuais daquele diálogo. 
Neste sentido, o testemunho é um importante recurso para a produção de narrativas orientadas à imersão. Segundo Frosh e Pinchevski (2009), o testemunho é capaz de transportar a experiência para uma linguagem. Na mídia, ele ajuda a reportar experiências e realidades distantes de outras pessoas. Peters (2009) identifica quatro modalidades de experiência subsidiadas por testemunhos: "estar lá" (presente no tempo e espaço); transmissão ao vivo (presença no tempo e ausência no espaço); historicidade (presença no espaço e ausente no tempo); e gravação (ausência no tempo e espaço). Desta forma, pode-se testemunhar pela experiência em primeira pessoa - algo que o jornalismo imersivo tenta emular através da tecnologia, como a realidade virtual e a sensação de presença (DE LA PEÑA et al. 2010; SLATER, 2009) - ou pela visão de terceiros; quando estamos sujeitos às imprecisões de memória e criações intencionais.

No jornalismo, o testemunho define, inclusive, um movimento no jornalismo contra-hegemônico na América Latina nos anos 1970. Denominado testimonio, o formato investe no testemunho de grupos marginalizados e perseguidos politicamente em seus países de origem para a criação de peças centradas nestes relatos. O modelo, além de romper com as regras industriais da produção de notícias, baseadas na objetividade, representa uma diversificação também do novo jornalismo estadunidense que emergiu duas décadas antes, conforme aborda Fonseca (2020). Entre os seus atributos estão técnicas e estratégias para a imersão no jornalismo, subjetividade explícita, pontos de vista, concentração em personagens, construção cênica, diálogos e fluxo de consciência (ASSUNÇÃO, 2016; GARCÍA, 2009). A peça do Correio* é fundamentalmente construída com base no testemunho das vítimas de violência sexual, que frequentemente não encontram espaço e tempo na cobertura jornalística cotidiana para relatos tão detalhados e carregados de subjetividade.

A agência é outra característica destas narrativas jornalísticas orientadas à imersão. O conceito se refere a uma ação do usuário que tenha impacto na ocorrência da narrativa e que ele possa observar o resultado das suas escolhas (MURRAY, 1997). Na peça em vídeo $360^{\circ}$ do The Guardian, significa que os agentes produtivos precisam se preocupar com todo o ambiente porque o usuário terá a liberdade de escolher seu próprio enquadramento durante a exibição.

Desta forma, intersubjetividade, dialogismo, testemunho e agência foram identificados nas práticas de produção jornalísticas orientadas à imersão em plataformas digitais. Todas elas impactam a tomada de decisão de agentes produtivos na produção das peças, dos usuários nos processos de fruição e, consequentemente, na geração de conhecimento de produtos contemporâneos.

A síntese da nossa proposta de uma epistemologia da prática do jornalismo orientado à imersão baseia-se na experiência. Trata-se de um conceito frequentemente acionado em trabalhos acadêmicos e entre profissionais do mundo do trabalho, segundo observado em Fonseca, Lima e Barbosa (2019), para refletir sobre a imersão no jornalismo. Além disso, envolve múltiplas perspectivas e não apenas a experiência dos usuários na interação com os produtos. O complexo debate sobre a experiência pode ser trabalhado pelo viés da estética, quando aborda questões emocionais na tensão da produção e fruição (DEWEY, 1980); da sociologia, com foco na vivência (QUÉRÉ, 2010); na filosofia, com a crítica do enfraquecimento da experiência no mundo moderno (BENJAMIN, 1994), entre outros campos de pesquisa.

Benjamin (1994) e Bondía (2002) argumentam que cada vez mais estamos empobrecendo as experiências. Distração, dispersão e fragmentação são alguns elementos que ajudam a explicar este momento. Além disso, o excesso de informação, de opinião, a falta de tempo e o excesso de trabalho também contribuem para o enfraquecimento da experiência, assim como o jornalismo, pelas suas características no modo de reportar. 
As narrativas jornalísticas orientadas à imersão, por outro lado, vão no caminho de manter a continuidade e a complexidade da experiência, segundo Dewey (1980). Este tipo de produto investe em conteúdos contextualizados, aprofundados, não-fragmentados e que oferecem um conhecimento sobre a realidade social em sua inteireza. Os agentes produtivos exploram técnicas e estratégias próprias de tradições de pesquisa como a sociologia, antropologia e historiografia, bem como de recursos das plataformas digitais para incrementar as experiências de imersão dos usuários.

Além de uma produção contextualizada e de métodos de apuração que buscam um acesso mais rigoroso aos acontecimentos, a forma de conhecimento do jornalismo orientado à imersão se distingue de outros modelos ao não omitir emoções, ao buscar o envolvimento corpóreo e/sensível, ao explorar formatos narrativos híbridos e compreender que a nossa experiência com o mundo é complexa e multidimensional. Algumas características permanecem, como o trabalho com o conhecimento do senso comum, o menor rigor que a ciência formal e a universalidade, apontadas por Meditsch (2002), bem como a singularidade e o vínculo com o tempo presente abordados em Genro Filho (1987). Por outro lado, algumas limitações e barreiras surgem como a viabilidade econômica deste modelo que demanda maior tempo e custo de produção e o problema da atenção dispersa e fragmentada, uma forte característica da interação no ambiente digital (FONSECA, 2020), que não converge com processos de imersão.

\section{Conclusões}

Este trabalho teve como objetivo propor uma epistemologia da prática jornalística orientada à imersão. Ao longo da nossa pesquisa doutoral, percebeu-se que este tipo de produção tem processos que não convergem com a epistemologia da objetividade. Neste artigo, dois casos ajudaram a ilustrar resultados observados em produtos jornalísticos que investem esforços para incrementar a imersão. Análise de produtos e entrevistas semiestruturadas com agentes produtivos subsidiaram as reflexões.

Produtos construídos a partir deste modelo da epistemologia da experiência no jornalismo orientado à imersão têm um lugar específico dentro do campo e nos meios, bem como objetivos particulares. Este tipo de peça noticiosa explora a intersubjetividade e o dialogismo, bem como os recursos do testemunho e da agência, permitida pelas plataformas digitais e acabam valorizando a experiência.

Do ponto de vista do conhecimento gerado, é possível salientar que a fundamentação no senso comum permanece, mas a busca pela credibilidade e verossimilhança não perpassam um modelo baseado unicamente nos procedimentos da objetividade - cuja as características são supressão de adjetivações, frases diretas e concisas, omissão de detalhes, entre outros que operam na contramão da experiência. Nas narrativas orientadas à imersão, há uma inclinação em acionar o envolvimento emocional, sensório e até corporal do usuário, para a criação de conexões duradouras, profundas e que simulem ou sejam inspiradas pela experiência no mundo sensível. $\mathrm{O}$ foco está no encontro que permite a troca de conhecimentos entre fontes e repórteres e narrativas e sujeitos.

É preciso destacar também que a produção jornalística orientada à imersão tem suas limitações. O amplo tempo e custos nos processos produtivos destas peças, em um cenário de crise no jornalismo industrial, faz com que este tipo de produto não seja realizado e ofertado com frequência pelos meios jornalísticos. Além disso, a atenção dispersa e fragmentada que caracteriza as interações na comunicação digital não converge com as particularidades do processo de imersão do usuário no momento de decodificação do produto. 
Futuros esforços de investigação devem aprofundar esta proposta e agregar características de produtos em diferentes formatos narrativos que exploram recursos para incrementar a imersão. Além disso, um estudo sobre os valores e sobre as práticas, tendo em vista um acompanhamento mais próximo da produção destas peças - e não baseado apenas no relato e dependência da memória dos agentes produtivos.

\section{Referências}

ALLAN, R. J.; DE JONG, I. J. F; DE JONGE, C. C.. From Enargeia to Immersion: The Ancient Roots of a Modern Concept. Style, v. 51, n. 1, p. 34-51, 2017.

ASSUNÇÃO, L. F. Testimonio como movimento e fait divers como instrumento: um outro processo produtivo jornalístico. XXV Encontro Anual da Compós. Anais... Goiânia, Goiás: Compós, 2016.

BENÍTEZ DE GRACIA, M. J.; HERRERA DAMAS, S. El reportaje inmersivo a través de video en $360^{\circ}$ : caracterización de una nueva modalidad de un género periodístico clásico. XXIII Congreso Internacional de la SEP. Anais... Salamanca, 2017.

BENJAMIN, W. O Narrador: Considerações sobre a obra de Nikolai Leskov. In: BENJAMIN, W. (Ed.). Magia e técnica, arte e política: ensaios sobre literatura e história da cultura. São Paulo: Brasiliense, 1994. p. 197-221.

BIZZOCCHI, J. Games and Narrative: An Analytical Framework. Loading-The Journal of the Canadian Games Studies Association, v. 1, n. 1, 2007.

BONDÍA, J. L. Notas sobre a experiência e o saber de experiência. Revista Brasileira de Educação, n. 19, p. 20-28, 2002.

BOUKO, C. Interactivity and immersion in a media-based performance. Journal of Audience \& Reception Studies, v. 11, n. 1, p. 254-269, 2014.

BOURDIEU, P. Sobre a televisão: seguido de a influência do jornalismo e os jogos olímpicos. Rio de Janeiro: Zahar, 1997.

BRADSHAW, P. Instantaneidade: Efeito da rede, jornalistas mobile, consumidores ligados e o impacto no consumo, produção e distribuição. In: CANAVILHAS, J. M. M. (Ed.). Webjornalismo: 7 caraterísticas que marcam a diferença. Covilhã, Portugal: Livros LabCom, 2014. p. 111-136.

BRANCH, J. Snow Fall - The Avalanche at Tunnel Creek. New York Times, 2012. Disponível em: https://www.nytimes.com/projects/2012/snow-fall/index.html\#/?part=tunnel-creek. Acesso em: 08 jan. 2020.

BRAGATTO, S. Jornalismo literário como literatura: o "Novo Jornalismo" de Armies of the Night, de Norman Mailer. [s.l.] (Dissertação de mestrado em Literatura), Universidade de São Paulo, São Paulo, 2007.

BROWN, E.; CAIRNS, P. A grounded investigation of game immersion. Extended abstracts of the 2004 conference on Human factors and computing systems - CHI '04. Anais... 2004. 
CANAVILHAS, J. M. M. Webjornalismo. Da pirâmide invertida à pirâmide deitada. BOOC, p. 1-17, 2007.

CARLSON, M. Journalistic Authority: Legitimating News in the Digital Era. New York: Columbia University Press, 2017.

CARLSON, M. Automating judgment? Algorithmic judgment, news knowledge, and journalistic professionalism. New Media \& Society, v. 20, n. 5, p. 1755-1772, 22 mai. 2018.

CARLSON, M. Journalistic epistemology and digital news circulation: Infrastructure, circulation practices, and epistemic contests. New Media \& Society, v. 22, n. 2, p. $230-246,20$ fev. 2020.

CASTAÑON, G. Introdução à epistemologia. São Paulo: Editora Pedagógica Universitária (EPU), 2007.

CHALABY, J. The invention of journalism. New York, USA: St. Martin’s Press, 1998.

CRAMER, J.; MCDEVITT, M. Ethnographic Journalism. In: HARTIN IORIO, S. (Ed.). Qualitative Resarch in Journalism. Taking It to the Streets. Mahwah: Lawrence Erlbaum Associates Publishers, 2004. p. 127-143.

DE LA PEÑA, N. et al. Immersive journalism: Immersive virtual reality for the first-person experience of news. Presence: Teleoperators and Virtual Environments, v. 19, n. 4, p. 291-301, 2010.

DEUZE, M. What is multimedia journalism? Journalism Studies, v. 5, n. 2, p. 139-152, mai. 2004.

DEUZE, M. Understanding Journalism as Newswork: How It Changes, and How It Remains the Same. Westminster Papers in Communication and Culture, v. 5, n. 2 , p. $4-24,2008$.

DEUZE, M.; WITSCHGE, T. Beyond journalism: Theorizing the transformation of journalism. Journalism, 2018.

DEWEY, J. Arts as experience. Nova Iorque: Perigee Books, 1980.

DOOLEY, L. M. Case Study Research and Theory Building. Advances in Developing Human Resources, v. 4, n. 3, p. 335-354, 2002.

DURHAM, M. G. On the Relevance of Standpoint Epistemology to the Practice of Journalism: The Case for "Strong Objectivity". Communication Theory, v. 8, n. 2, p. 117-140, mai. 1998.

EKSTRÖM, M. Epistemologies of TV journalism: A theoretical framework. Journalism, v. 3, n. 3, p. 259-282, 2002.

EKSTRÖM, M.; WESTLUND, O. The Dislocation of News Journalism: A Conceptual Framework for the Study of Epistemologies of Digital Journalism. Media and Communication, v. 7, n. 1, p. 259, 21 mar. 2019. 
ERMI, L.; MÄYRÄ, F. Fundamental Components of the Gameplay Experience: Analysing Immersion. Changing Views: Worlds in Play. Anais... Vancouver, Canada, 2005.

ETTEMA, J. S.; GLASSER, T. L. On the epistemology of investigative journalism. Annual Meeting of the Association for Education in Journalism and Mass Communication. Anais... ERIC, 1984.

FROSH, P.; PINCHEVSKI, A. Introduction: Why media witnessing? Why now. In: FROSH, P.; PINCHEVSKI, A. (Org.). Media witnessing. Basingstoke: Palgrave Macmillan, 2009, p. 1-19.

FONSECA, A. dos A. A imersão como categoria estruturante e indutora de inovações no jornalismo em redes digitais. 2020. 475f. Tese (Doutorado em comunicação) - Faculdade de Comunicação, Universidade Federal da Bahia, Salvador, 2020.

FONSECA, A. dos A. A inovação no jornalismo em revistas para tablets: uma análise a partir das affordances e da convergência de conteúdos jornalísticos. 2015. 256 f. Dissertação (Mestrado em Comunicação), Universidade Federal da Bahia, Salvador, 2015.

FONSECA, A. dos A.; LIMA, L.; BARBOSA, S. Uma proposta de framework teórico para análise da experiência no jornalismo imersivo. Anais... Porto Alegre, 2019.

GARCÍA, K. A. Periodismo, arte y testimonio. Operación Masacre: el legado de un escritor anfibio. Revista Nexus Comunicación, n. 5, 2009.

GENRO FILHO, A. O segredo da pirâmide: para uma Teoria Marxista do Jornalismo. 1987. 276 f. Dissertação (Mestrado em Sociologia), Universidade Federal de Santa Catarina, Florianópolis, 1987.

GERRIG, R. J. Experiencing narrative worlds. Boston: Yale University Press, 1993.

GODLER, Y.; REICH, Z.; MILLER, B. Social epistemology as a new paradigm for journalism and media studies. New Media \& Society, v. 22, n. 2, p. 213-229, 20 fev. 2020.

GORDON, R. The meanings and implications of Convergence. Digital journalism: Emerging media and the changing horizons of journalism, v. 57, 2003.

GRAU, O. Virtual Art: from illusion to immersion. Massachusetts: MIT press, 2003.

GUERRA, J. A objetividade jornalística. [s.l.] (Dissertação de mestrado em Comunicação), Universidade Federal da Bahia, Salvador, 1998.

HERMANN, A. K. Ethnographic journalism. Journalism: Theory, Practice \& Criticism, v. 17, n. 2, p. 260-278, 11 fev. 2016.

HIIPPALA, T. The Multimodality of Digital Longform Journalism. Digital Journalism, v. 5, n. 4, p. 420-442, 21 abr. 2017.

HODGSON, K. Immersive storytelling: How 360-degree video storytelling is helping to redefine journalism. [s.l.] (Tese de doutorado em Artes, Comunicação e Tecnologia), University of Alberta, USA, 2017. 
KOLODZY, J. Practicing Convergence Journalism: An introduction to cross-media storytelling. Nova Iorque: Routledge, 2012.

KOVACH, B.; ROSENSTIEL, T. The elements of journalism: What newspeople should know and the public should expect. Nova Iorque: Crowen, 2001.

LABASSE, B. A Epistemologia do Jornalismo Pode Delimitar seu Território Discursivo? Parágrafo: Revista Científica de Comunicação Social da FIAM-FAAM, v. 5, n. 1, p. 6-28, 2017.

LEVISOLO, H. "Epistemologia prática" no campo da comunicação. Revista Contracampo, n. 07, 16 dez. 2008.

LEWIS, S. C.; WESTLUND, O. Big Data and Journalism. Digital Journalism, v. 3, n. 3, p. 447-466, 4 mai. 2015.

LIMA, E. P. Páginas Ampliadas: o Livro-Reportagem como Extensão do Jornalismo e da Literatura. São Paulo: Unicamp, 1993.

LONGHI, R.; WINQUES, K. O lugar do longform no jornalismo online: Qualidade versus quantidade e algumas considerações sobre o consumo. Brazilian Journalism Research, v. 1, n. 1, p. 110-127, 2015.

LÓPEZ HIDALGO, A.; FERNÁNDEZ BARRERO, M. Á. Os Caminhos da Imersão na Era do Jornalismo Transmidiático: do papel à realidade virtual. Parágrafo: Revista Científica de Comunicação Social da FIAM-FAAM, v. 4, n. 2, p. 103-111, 2016.

MACHADO, A. Regimes de Imersão e Modos de Agenciamento. XXV Congresso Brasileiro de Ciências da Comunicação. Anais... Salvador: 2002.

MAIA, M. R. A regra da transparência como elemento democratizador no processo da produção jornalística. Brazilian Journalism Research, v. 4, n. 2, p. 132-152, 30 dez. 2008.

MARAS, S. Objectivity in journalism. Cambridge: Polity, 2013.

MARTINEZ, M. Jornalismo Literário: revisão conceitual, história e novas perspectivas. Intercom: Revista Brasileira de Ciências da Comunicação, v. 40, n. 3, p. 21-36, dez. 2017.

MATHESON, D. Weblogs and the Epistemology of the News: Some Trends in Online Journalism. New Media \& Society, v. 6, n. 4, p. 443-468, 30 ago. 2004.

MATHESON, D.; WAHL-JORGENSEN, K. The epistemology of live blogging. New Media \& Society, v. 22, n. 2, p. 300-316, 20 fev. 2020.

MEDINA, C. A arte de tecer o presente: narrativa e cotidiano. São Paulo: Summus Editorial, 2003.

MEDINA, C. Narrativas da Contemporaneidade: Epistemologia do Diálogo Social. Tríade: comunicação, cultura e mídia, v. 2, n. 4, p. 8-22, 2014.

MEDITSCH, E. O jornalismo é uma forma de conhecimento? Media \& Jornalismo. v 1, n. 1, p. 9-22, 2002. 
MIELNICZUK, L. Jornalismo na web: uma contribuição para o estudo do formato da notícia na escrita hipertextual. Tese (Doutorado em comunicação) - Faculdade de Comunicação, Universidade Federal da Bahia, Salvador, 2003.

MURRAY, J. H. Hamlet on the Holodeck: The Future of Narrative in Cyberspace. New York, USA: Free Press, 1997.

PARK, R. News as a Form of Knowledge: A Chapter in the Sociology of Knowledge. American Journal of Sociology, v. 45, n. 5, p. 669-686, 1940.

PETERS, J. D. W. In: FROSH, P.; PINCHEVSKI, A. (Org.). Media witnessing. Basingstoke: Palgrave Macmillan, 2009.

PEW, M. E. Public Service Journalism. Journalism Bulletin, v. 8, n. 1, p. 89-99, 29 mar. 1931.

PIVA, A. et al. Origens do conceito de Intersubjetividade: Uma trajetória entre a Filosofia e a Psicanálise Contemporânea. Contemporânea - Psicanálise e Transdisciplinaridade, n. 9, p. 71-91, 2010.

QUÉRÉ, L. O caráter impessoal da experiência. In: LEAL, Bruno Souza; MENDONÇA, Carlos Camargos; GUIMARÃES, César (Eds.) Entre o sensível e o comunicacional. Belo Horizonte: Autêntica, 2010. p. 19-38.

RUDIGER, F. Epistemologia “da" Comunicação: elementos para a crítica de uma fantasia acadêmica. Revista FAMECOS, v. 21, n. 2, p. 395, 9 set. 2014.

RYAN, M.-L. Impossible Worlds and Aesthetic Illusion. In: WOLF, W.; BERNHART, W.; MAHLER, A. (Eds.). Immersion and Distance: Aesthetic Illusion in Literature and Other Media. Amsterdam: Rodopi, 2013. p. 136-150.

RYAN, M.-L. Narrative as virtual reality 2: Revisiting immersion and interactivity in literature and electronic media. Baltmore: JHU Press, 2015. v. 2

SALAVERRÍA, R. Multimedialidade: informar para cinco sentidos. In: CANAVILHAS, J. M. M. (Ed.). Webjornalismo: 7 caraterísticas que marcam a diferença. Covilhã, Portugal: Livros LabCom, 2014. p. 27-54.

SCHUDSON, M. News and democratic society: past, present, and future. The Hedgehog Review, v. 10, n. 2, p. 7-21, 2008.

SINGER, J. B. Strange bedfellows? The diffusion of convergence in four news organizations. Journalism Studies, 2004.

SLATER, M. Place illusion and plausibility can lead to realistic behaviour in immersive virtual environments. Philosophical Transactions of the Royal Society B: Biological Sciences, 2009.

SPLENDORE, S. Quantitatively Oriented Forms of Journalism and Their Epistemology. Sociology Compass, v. 10, n. 5, p. 343-352, mai. 2016.

SPONHOLZ, L. Jornalismo, Conhecimento e Objetividade: Além do Espelho e das Construções. Florianópolis, SC: Insular, 2009. 
TAMBOSI, O. Elementos para uma epistemologia do jornalismo. Intercom-Revista Brasileira de Ciências da Comunicação, v. 26, n. 2, 2003.

TÁRCIA, L. Narrativa Transmídia em Jornalismo de Imersão e Newsgame. 9o Encontro Nacional de Pesquisadores em Jornalismo. Anais... Rio de Janeiro: 2011.

TUCHMAN, G. Objectivity as strategic ritual: An examination of newsmen's notions of objectivity. American Journal of sociology, v. 77, n. 4, p. 660-679, 1972.

YIN, R. K. Estudo de Caso: Planejamento e Métodos. Porto Alegre: Bookman editora, 2015. 